\title{
Efficacy and safety of decitabine in combination with G-CSF, low-dose cytarabine and aclarubicin in newly diagnosed elderly patients with acute myeloid leukemia
}

Jianyong $\mathrm{Li}^{1,2, *}$, Yaoyu Chen ${ }^{1,2, *}$, Yu Zhu ${ }^{1,2}$, Jianfeng Zhou ${ }^{3}$, Yanli Xu ${ }^{4}$, Yan Li ${ }^{5}$, Kang $\mathbf{Y u}^{6}$, Ling Pan7, Jianmin Wang ${ }^{8}$, Jiahua Ding ${ }^{9}$, Jian $\mathbf{G u}^{10}$, Shanhua Zhou ${ }^{11}$, Jinning Shi ${ }^{12}$, Ming Hong ${ }^{1,2}$, Ji Xu $\mathbf{u}^{1,2}$, Liangqin Pan ${ }^{1,2}$, Limin Duan ${ }^{1,2}$, Run Zhang ${ }^{1,2}$, Sujiang Zhang $^{1,2}$, Huayuan Zhu ${ }^{1,2}$, Hua Lu ${ }^{1,2}$, Peng Liu ${ }^{1,2}$, Hongxia Qiu ${ }^{1,2}$, Hanxin Wu ${ }^{1,2}$ and Sixuan Qian ${ }^{1,2}$

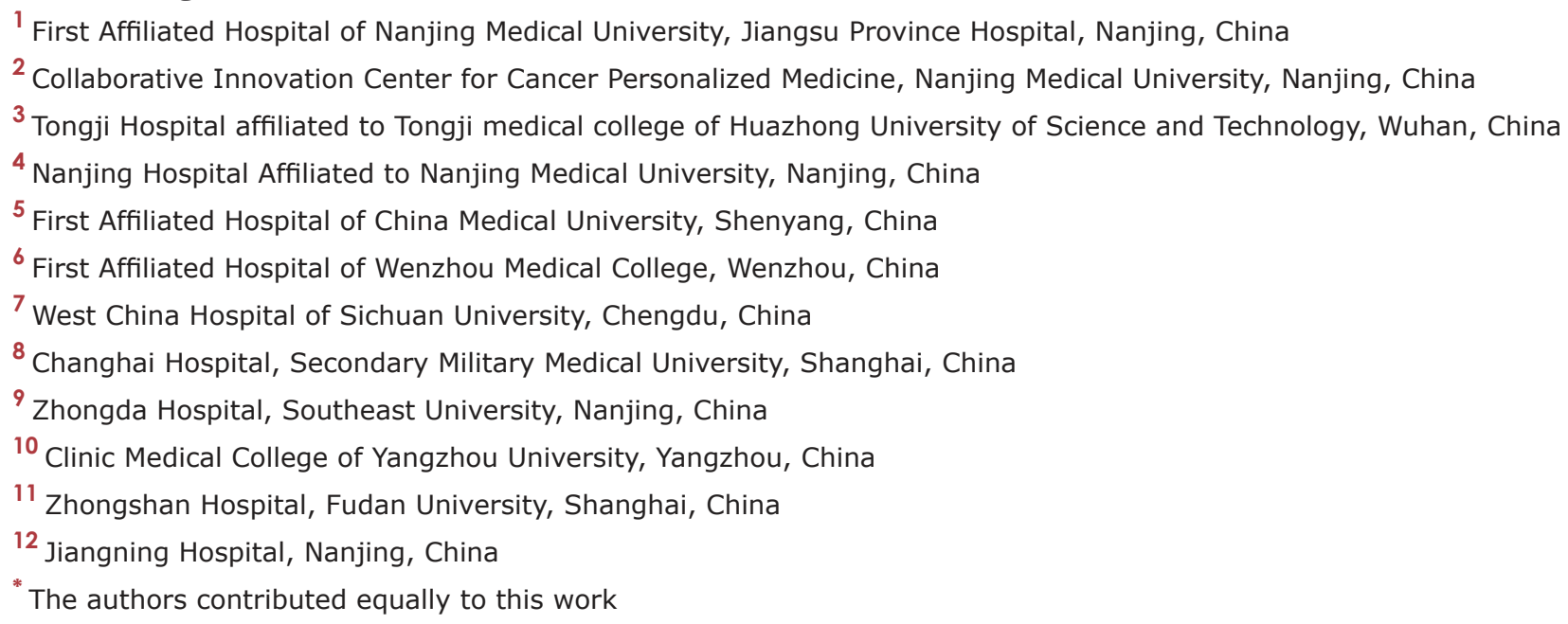

Correspondence to: Sixuan Qian, email: qiansx@medmail.com.cn

Keywords: D-CAG, elderly patients, AML

Received: December 01,2014 Accepted: January 13,2015 Published: January 31, 2015

This is an open-access article distributed under the terms of the Creative Commons Attribution License, which permits unrestricted use, distribution, and reproduction in any medium, provided the original author and source are credited.

\section{ABSTRACT}

Purpose: This prospective phase II, open label, study was designed to assess the efficacy and safety of D-CAG induction treatment for elderly patients with newly diagnosed AML.

Experimental Design: All patients in this study were treated with decitabine of $\mathbf{1 5}$ $\mathrm{mg} / \mathrm{m}^{2}$ for 5 days and G-CSF for priming, in combination with cytarabine of $10-\mathrm{mg} /$ $\mathrm{m}^{2} \mathrm{q} 12 \mathrm{~h}$ for 7 days and aclarubicin of $10 \mathrm{mg} /$ day for 4 days (D-CAG).

Results: Among 85 evaluable patients, overall response rate (ORR) and complete remission (CR) were $82.4 \%$ and $64.7 \%$, respectively, after 1 cycle of therapy. The ORR in patients aged $<70$ years was $83.0 \%$ and $81.6 \%$ in patients aged $\geq 70$ years. There was a significantly longer median overall survival (OS) in patients with response (16 months) than in those without response ( 7 months, $p<0.0001$ ). The os for patients aged $\geq 70$ years and 60-69 years was 10 months and 12 months, respectively $(p=0.4994)$. The two-year OS probability was $19.2 \%$ and the twenty-month survival rate was $33.8 \%$. Induction mortality of D-CAG treated elderly patients with AML is 4.4\%.

Conclusion: D-CAG regimen was well tolerated and showed a promising clinic efficacy in elderly patients with AML ( $\geq 70$ years). 


\section{INTRODUCTION}

Acute myeloid leukemia (AML) in the elderly population (aged $\geq 70$ years) has a high incidence with $>20$ cases per 100000 patients every year[1]. The combination of cytarabine and anthracycline remains the cornerstone of chemotherapy in those patients and this treatment confers remission in up to $60 \%$ of elderly patients with de novo disease and $40 \%$ with secondary AML[2]. However, many elderly patients develop disease recurrence and die of either disease progression or associated complications. Therefore, those strategies including intensive chemotherapy, low-dose cytarabine, and palliative care are not the appealing approaches for most elderly patients with AML[3].

The combination of novel drugs and low-intensity chemotherapy were developed to reduce the early mortality and improve the benefit-risk ratio for longterm survival in elderly AML patients. Among them, DNA hypomethylating agents showed better single-agent clinical activities in both myelodysplastic syndromes (MDS) and AML, with high survival rates and low risks associated with induction chemotherapy [4-6]. Decitabine, a hypomethylating agent, inhibits DNA methyltransferase 1(DNMT1)[7], reactivates of silenced genes, and induces differentiation of leukemia cells[8]. In clinic, decitabine treatment decreased methylation and induced a better clinical response [9]. Several clinical trials indicated that low-dose of decitabine $\left(15-20 \mathrm{mg} / \mathrm{m}^{2} /\right.$ day, the optimal demethylation dose in vitro) led to a significantly better response rate [4-6, 10-12]. Although the mechanistic basis for the clinical activity of decitabine has not been precisely defined, the clinical and biologic activities of decitabine are very encouraging $[10,12,13]$.

Our previous studies revealed that the standarddose of CAG regimen consisting of low-dose cytarabine and aclarubicin in combination with granulocyte colonystimulating factor (G-CSF) priming as an induction therapy was well-tolerated by patients and led to a complete remission (CR) rate of $50.0 \%$ in patients aged $\geq 70$ years, and a CR rate of $40.0 \%$ in patients with unfavorable cytogenetic aberrations[14]. In this study, we conducted a phase II trial that evaluated the efficacy and safety of decitabine in combination with modified CAG regimen (low-dose cytarabine and aclarubicin) in elderly patients with AML.

\section{RESULTS}

\section{Patient characteristics}

From October 2010 through March 2013, a total of 91 patients with age from 60 to 87 years (median age: 68) were enrolled onto the study (Fig.1). Among those cases, 42 patients $(46.2 \%)$ were $\geq 70$ years of age. Baseline characteristics are shown in Table 1. According to WHO classification, 91 patients had AML (53 de novo, 38 secondary AML). Karyotype included 55 patients $(60.4 \%)$ with diploid cytogenetics, 15 (16.5\%) with chromosome $-5 /-7$ or complex cytogenetic abnormalities, and $12(13.2 \%)$ with other miscellaneous chromosomal abnormalities. Overall, 70 patients $(76.9 \%)$ were considered ineligible for intensive chemotherapy (aged $>70$ years, ECOG PS $\geq 3$, comorbidity score $\geq 2$, or adverse cytogenetic).

\section{Treatment outcomes}

\section{Response rates for all patients or selected subgroups}

Patient responses were summarized in Fig. 2. There were 85 patients evaluable for response assessment following the D-CAG induction therapy and had an overall response rate (ORR) of $82.4 \%$ after the first cycle. Among them, 55 (64.7\%) achieved CR and 15 (17.7\%) had PR. After the second cycle, 11 patients with PR acquired CR. The ORR in patients with aged $<70$ years was $83.0 \%$ and $81.6 \%$ in patients with aged $\geq 70$ years. The $\mathrm{CR}$ in patients with presenting $\mathrm{WBC}>30 \times 10^{9} / \mathrm{L}$ (range, 30.9-239 $\times$ $10^{9} / \mathrm{L}$ ) was $68.4 \%$ (13 of 19 ). The CR was observed in all cytogenetic subsets. For patients with a normal karyotype, $84.3 \%$ (43 of 51) achieved CR. 18 of 63 patients with CR (28.6\%) had abnormal karyotypes at baseline with complete cytogenetic responses (CCyR, 0\% abnormal metaphase) of $77.8 \%$ (14 of 18). Patients with complex karyotypes (defined as $\geq 3$ abnormalities) had an ORR of $92.9 \%(\mathrm{CR}, 78.6 \%)$ and 7 of 8 patients with chromosome $-5 /-7(87.5 \%)$ achieved CR.

\section{Overall survival of elderly patients with AML}

Upon final analysis (April 30, 2014), the median OS for all patients was 10 months (range, 1-42 months) with a 1 - and 2-year OS probability of $46.23 \%$ and $19.16 \%$, respectively (Fig. 3A). Median OS was 10 months (range, 1-42 months) for patients aged $\geq 70$ years and 12 months (range, 1-39 months) for patients aged 60-69 years $(p=0.4994,95 \% \mathrm{CI}=0.7194$ to 1.966$)$ (Fig. 3B). There was a significantly longer median OS in responders than in non-responders (16 vs 7 months, $p<0.0001,95 \%$ $\mathrm{CI}=0.0397$ to 0.3198 ) (Fig. 3C). However, survival was shorter for patients with poor karyotype (-5/-7 or complex karyotype) in comparison with patients with normal karyotype ( $p=0.0269,95 \% \mathrm{CI}=0.1788$ to 0.9007 , Fig. 3D). 
Table 1: Patient Characteristics

\begin{tabular}{|c|c|c|c|}
\hline Characteristics & No. & & $\%$ \\
\hline \multicolumn{4}{|l|}{ Age,years } \\
\hline median & & 68 & \\
\hline range & & $60-87$ & \\
\hline Male sex & 56 & & 61.5 \\
\hline \multicolumn{4}{|l|}{ Diagnosis (WHO) } \\
\hline M1 & 11 & & 12.1 \\
\hline M2 & 45 & & 49.5 \\
\hline M4 & 7 & & 7.7 \\
\hline M5 & 16 & & 17.6 \\
\hline M6 & 12 & & 13.2 \\
\hline AML, de novo & 53 & & \\
\hline sAML & 38 & & \\
\hline Secondary MDS & 26 & & \\
\hline Secondary myeloproliferative disorders & 3 & & \\
\hline Secondary immune disease & 2 & & \\
\hline Secondary other tumor & 5 & & \\
\hline Complicated solid tumor & 2 & & \\
\hline \multicolumn{4}{|l|}{$\mathrm{WBC}, \times 10^{9} / \mathrm{L}$} \\
\hline Median & & 4.1 & \\
\hline Range & & $0.16-239.9$ & \\
\hline \multicolumn{4}{|l|}{ Platelets, $\times 10^{9} / \mathrm{L}$} \\
\hline Median & & 49 & \\
\hline Range & & 6-974 & \\
\hline \multicolumn{4}{|l|}{$\mathrm{Hb}, \times 10^{9} / \mathrm{L}$} \\
\hline Median & & 73 & \\
\hline Range & & $34-132$ & \\
\hline \multicolumn{4}{|l|}{ BM blasts } \\
\hline Median & & 47 & \\
\hline Range & & $22-95.2$ & \\
\hline \multicolumn{4}{|l|}{ karyotype-risk $(\mathrm{n}=)^{*}$} \\
\hline $\begin{array}{c}\text { Good } \\
\text { Intermediate }\end{array}$ & $\begin{array}{c}1 \\
66\end{array}$ & & $\begin{array}{c}1.1 \\
72.5\end{array}$ \\
\hline Poor & 15 & & 16.5 \\
\hline Unavailable & 9 & & 9.9 \\
\hline \multicolumn{4}{|l|}{ FLT3 mutational status } \\
\hline Wild-type FLT3 & 48 & & 52.7 \\
\hline FLT3-ITD mutation & 6 & & 6.6 \\
\hline Missing & 37 & & 40.7 \\
\hline \multicolumn{4}{|l|}{ NPM1 mutational status } \\
\hline Wild-type NPM1 & 39 & & 42.9 \\
\hline NPM1 mutation & 15 & & 16.5 \\
\hline Missing & 37 & & 40.7 \\
\hline \multicolumn{4}{|l|}{ CEBP $\alpha$ mutational status } \\
\hline Wild-type CEBP $\alpha$ & 48 & & 52.7 \\
\hline CEBP $\alpha$ mutation & 6 & & 6.6 \\
\hline Missing & 37 & & 40.7 \\
\hline
\end{tabular}

Abbreviations: BM: bone marrow; WBC, white blood count; ITD,internal tandem duplication; *Cytogenetic groups were defined as follows: favourable $-\mathrm{t}(8 ; 21)$, inv(16), irrespective of the presence of other abnormalities; adverse - monosomy 5 , monosomy 7 , del $(5 q)$, abnormal $3 q$, complex (5 or more chromosomal abnormalities); intermediate - all other abnormal karyotypes, normal karyotype. 


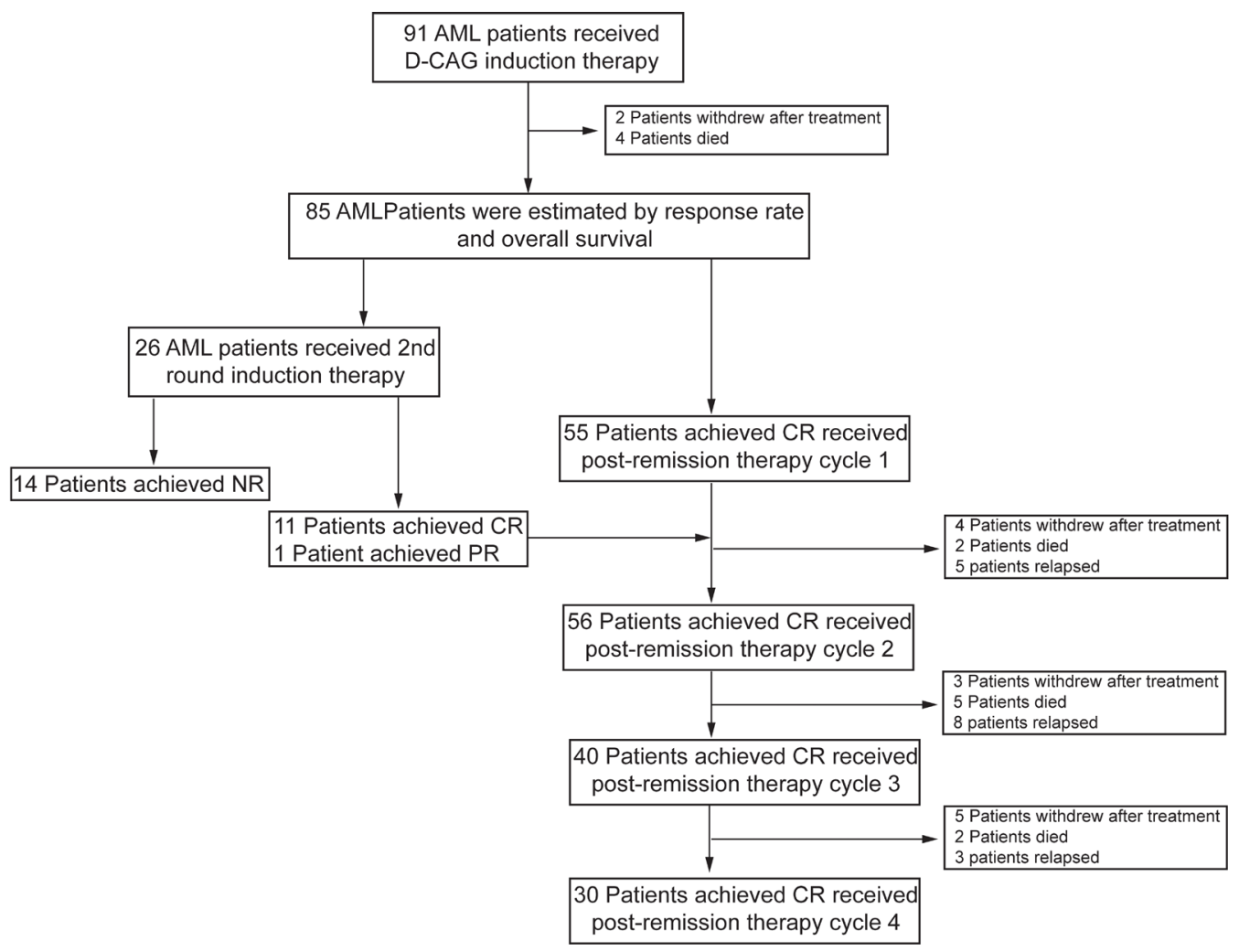

Figure 1: Enrollment and outcomes. 91 AML patients were treated with decitabine for 5 consecutive days (day 1-5) and G-CSF (day 0-9) for priming combined with cytarabine (day 3-9), aclarubicin for 4 days (day 3-6) (D-CAG). Up to two cycles of induction therapy were allowed if response was not achieved. Patients who achieved CR accepted the next cycle treatment for recovery of hematopoiesis and resolution of all toxicities. Patients who did not achieve CR or PR after the second cycle of induction therapy were offered alternative therapies. Post-remission therapy consisted of 4-6 cycles. Treatment was continued until relapse or progressive disease, death, or unacceptable toxicity occurred, or patients/physicians requested the discontinuity.

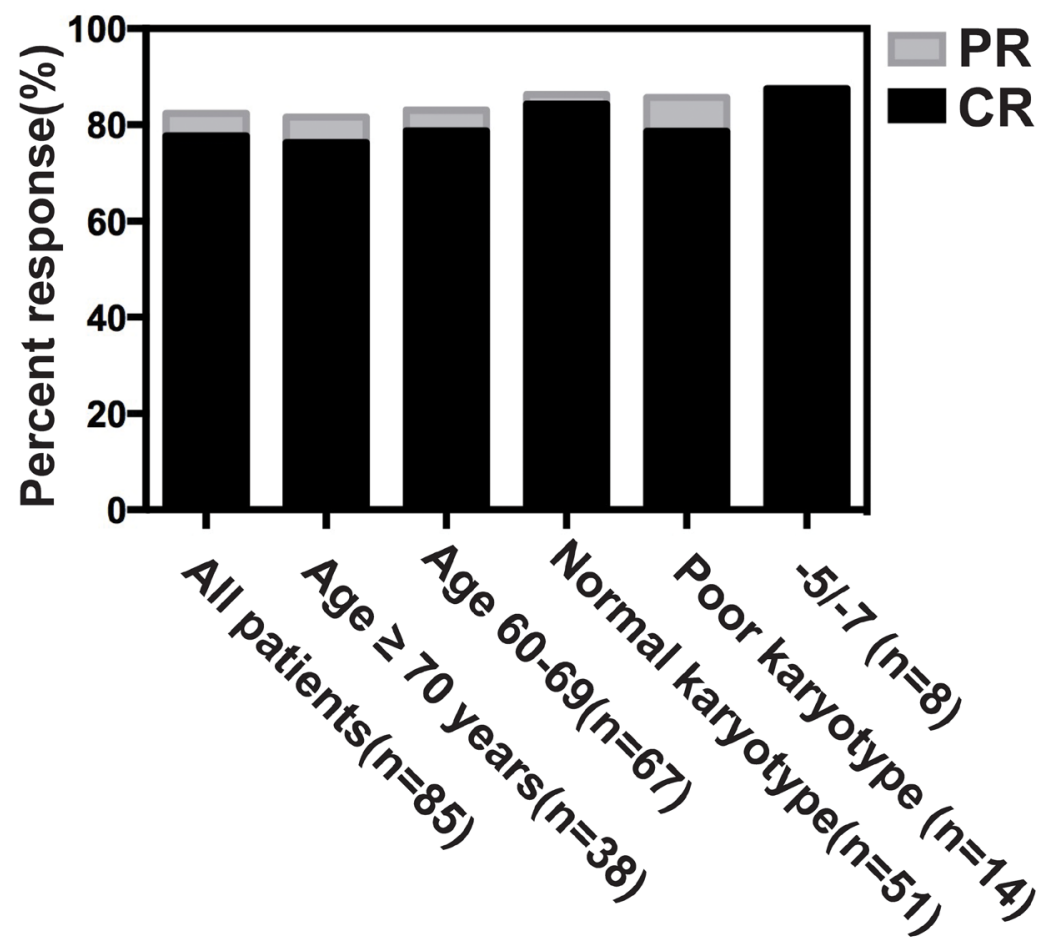

Figure 2: Response rates for all patients or selected subgroups . Percent response was noted by each bar graph. CR was noted in black, and additional patients with partial remission were noted in gray. The response rates for all patients, patients below or above the age of 70 years, patients with AML, and selected cytogenetic subgroups were shown respectively. 
Table 2: Prognostic factors for survival identified by multivariate analysis in older patients with AML

\begin{tabular}{|c|c|c|c|c|}
\hline Characteristics & Groups & HR & $95 \% \mathrm{CI}$ & Pvalue \\
\hline \multirow[t]{2}{*}{ Gender } & Female & 0.6923 & 0.08417 to 1.300 & 0.5293 \\
\hline & Male & 1 & & \\
\hline \multirow[t]{2}{*}{ Age (years) } & 70 & 1.189 & 0.7194 to 1.966 & 0.4994 \\
\hline & $60-69$ & 1 & & \\
\hline \multirow[t]{2}{*}{ WBC } & $\geq 30$ & 1.194 & 0.6375 to 2.237 & 0.5794 \\
\hline & $<30$ & 1 & & \\
\hline \multirow[t]{2}{*}{ BM Blasts } & $\geq 50$ & 1.122 & 0.6700 to 1.878 & 0.6622 \\
\hline & $<50$ & 1 & & \\
\hline \multirow[t]{2}{*}{ Karyotype } & intermediate & 0.3946 & 0.1766 to 0.8818 & 0.0234 \\
\hline & poor & 1 & & \\
\hline \multirow[t]{2}{*}{ ECOG } & $\geq 2$ & 2.099 & 1.232 to 3.578 & 0.0064 \\
\hline & $0-1$ & 1 & & \\
\hline \multirow[t]{2}{*}{ HCTCI } & $0-2$ & 0.5398 & 0.2985 to 0.9762 & 0.0414 \\
\hline & $3-6$ & 1 & & \\
\hline
\end{tabular}

\section{Gene mutation affected the overall survival of elderly patients with AML}

To investigate whether several known gene mutation might affect the OS of elderly AML patients under D-CAG treatment, we further analyzed the OS of D-CAG treated elderly AML patients by gene mutation, such as: Internal tandem duplications (ITDs) of the FMS-like tyrosine kinase 3 gene (FLT3), nucleophosmin $(N P M 1)$ mutation and CCAAT/enhancer binding protein alpha $(C E B P \alpha)$ mutation[15]. FLT3-ITDs are located

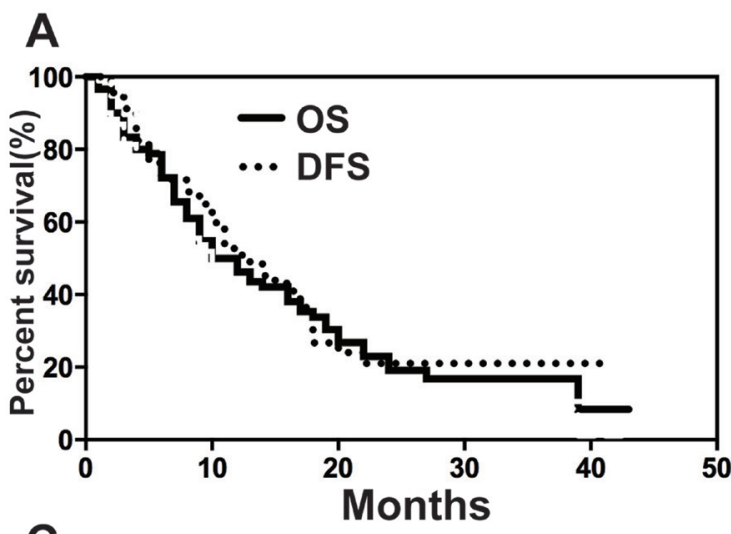

B
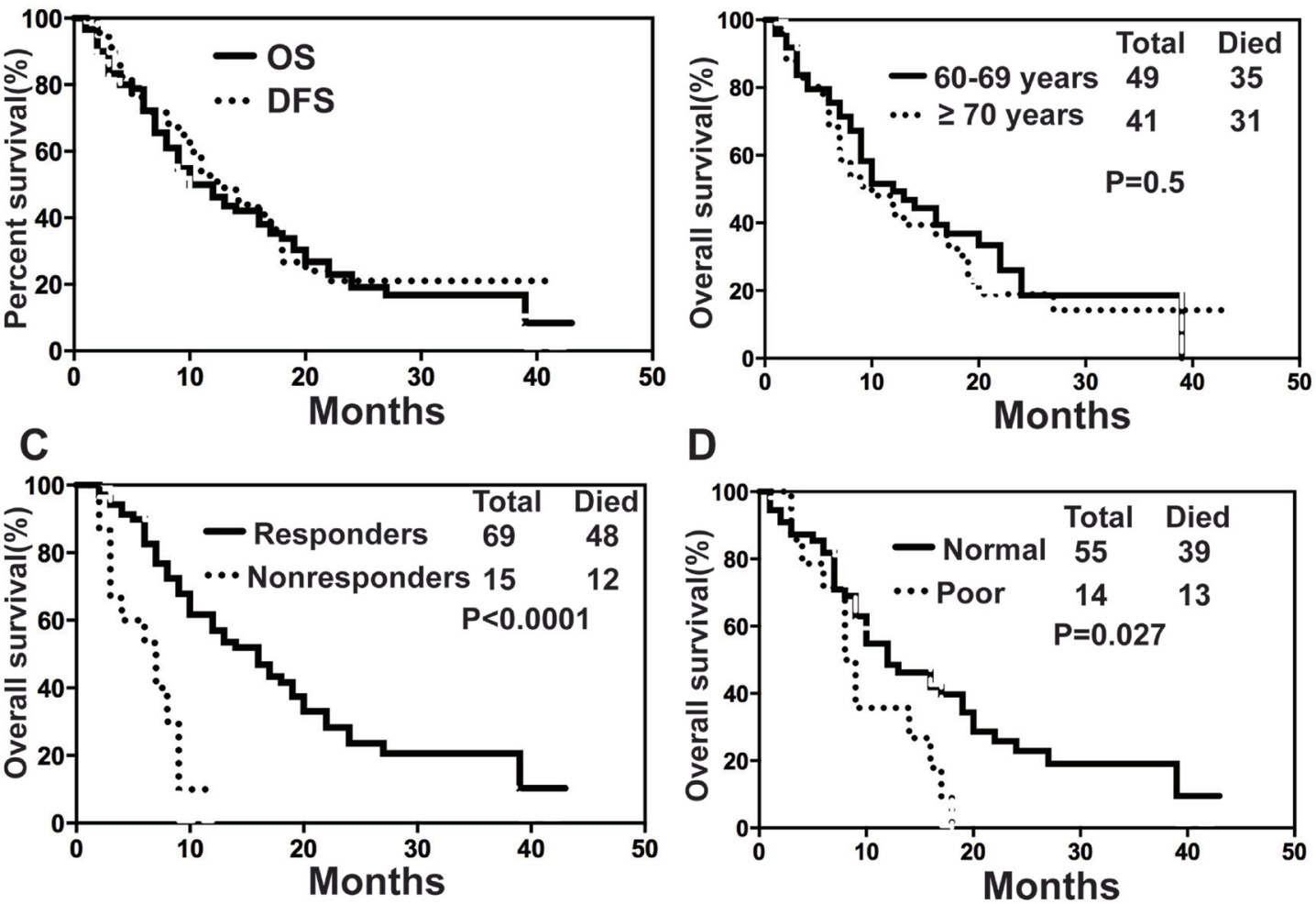

Figure 3: Overall survival. (A) all patients with AML, (B) patients $\geq 70$ years old or within 60-69 years old, (C) responder or nonresponder, (D) normal karyotype or poor karyotype 
Table 3: Most frequent side effects during induction therapy

\begin{tabular}{|c|c|c|}
\hline Side effect & $\begin{array}{c}\text { Grade II } \\
\text { No. Of patients }(\%)\end{array}$ & $\begin{array}{c}\text { Grades III/IV } \\
\text { No. Of patients }(\%)\end{array}$ \\
\hline Neutropenia & $13(14.3 \%)$ & $78(85.7 \%)$ \\
\hline Thrombocytopenia & $6(6.6 \%)$ & $85(93.4 \%)$ \\
\hline Febrile neutropenia & $57(62.6 \%)$ & $27(29.7 \%)$ \\
\hline Nausea, Vomiting & $13(14.3 \%)$ & - \\
\hline Hyperglycemia & $20(22.0 \%)$ & $5(5.5 \%)$ \\
\hline Acute pancreatitis & - & $1(1.1 \%)$ \\
\hline Intractable hiccup & - & $1(1.1 \%)$ \\
\hline Skin rashes & $3(3.3 \%)$ & - \\
\hline \multicolumn{3}{|l|}{ Liver dysfunction } \\
\hline Eleated enzymes & $13(14.3 \%)$ & $2(2.2 \%)$ \\
\hline Increasing bilirubin level & $7(7.7 \%)$ & - \\
\hline Creatinine elevation & $1(1.1) \%$ & - \\
\hline Cardiac dysfunction & - & $1(1.1 \%)$ \\
\hline Spsychiatric symptoms & $6(6.6 \%)$ & - \\
\hline
\end{tabular}

in exons 14 and 15 of the FLT3 gene and show a broad variation in the position of their insertion sites, as well as in number and sizes of the duplicated fragments[16]. The most common NPM1 mutations include type A mutations (TCTG) in $80 \%$, followed by type B (CATG) and type $\mathrm{D}$ (CCTG) mutations in about $10 \%$, and a spectrum of other mutations accounting for $10 \%$ of cases[17]. Two types of $C E B P \alpha$ mutations are predominant. $\mathrm{N}$-terminal frame-shift mutations lead to loss of translation of the full-length $42 \mathrm{kD} C E B P \alpha$ and the overexpression of a truncated, dominant negative $30 \mathrm{kD} C E B P \alpha$. C-terminal in-frame insertions/deletions prevent homo-dimerization or hetero-dimerization of $C E B P \alpha[18]$. In our study, we found that patients without FLT3-ITD mutation have a survival advantage in compared with those with FLT3ITD mutation ( $p=0.013,95 \% \mathrm{CI}=0.0296$ to 0.660 ) (Fig. 4A). A median OS for patients with wild-type NPM1 or with mutations in NPM1 only or with mutations in NPM1 and FLT3-ITD was 17, 15 and 5 months, respectively $(p=0.0778)$ (Fig. 4B). A significant OS difference was also observed in patients with $C E B P \alpha$ mutations vs. without $C E B P \alpha$ mutations ( $p=0.012,95 \% \mathrm{CI}=1.287$ to 7.551 ) (Fig. 4C).

\section{Prognostic factors for overall survival in elderly patients with AML}

In an exploratory subset analysis using a multivariate Cox proportional Hazards model, adverse cytogenetics $(\mathrm{p}=0.0234)$, poor performance status (ECOG PS of 3, $\mathrm{p}=0.0064)$, HCT-CI $(\mathrm{p}=0.0414)$ but not age, gender, WBC at diagnosis, or percentage of BM blasts $(50 \%)$, were identified as the independent adverse prognostic factors (Table. 2).

\section{Treatment-related toxicity}

\section{Serious Adverse Events}

Overall, D-CAG was well tolerated. Table. 3 showed the most frequent adverse events observed during induction therapy. The most common grade 3 and 4 toxicities included thrombocytopenia and neutropenia, while the incidence of non-hematological toxicities was low. Myelosuppression was commonly observed, and febrile neutropenia occurred in $92.3 \%$ of patients.

In patients with $\mathrm{CR}$, the median time was 16 days (range, 5-50 days) for platelet recovery and 23 days (range, 16-46 days) for granulocyte recovery. After a single induction, the platelet count in patients recovered briskly to the normal range, platelets rose and peaked above $500 \times 10^{9} / \mathrm{L}$ in 20 patients (all responders), and the count returned to the normal range within 7-10 days. During convalescence, no thrombotic complications were observed. 


\section{The factors caused the death of D-CAG treated elderly patients with AML}

64 of 91 patients died on study and reasons for patient death included relapsed disease $(50.6 \%)$, severe infections (16.5\%), refuse to treatment after the first cycle $(22 \%)$, refractory disease $(20.9 \%)$, cardiac dysfunction (3.3\%), and intracranial hemorrhage $(2.2 \%)$, multiple reasons $(6.6 \%)$. Within 4 weeks from the beginning
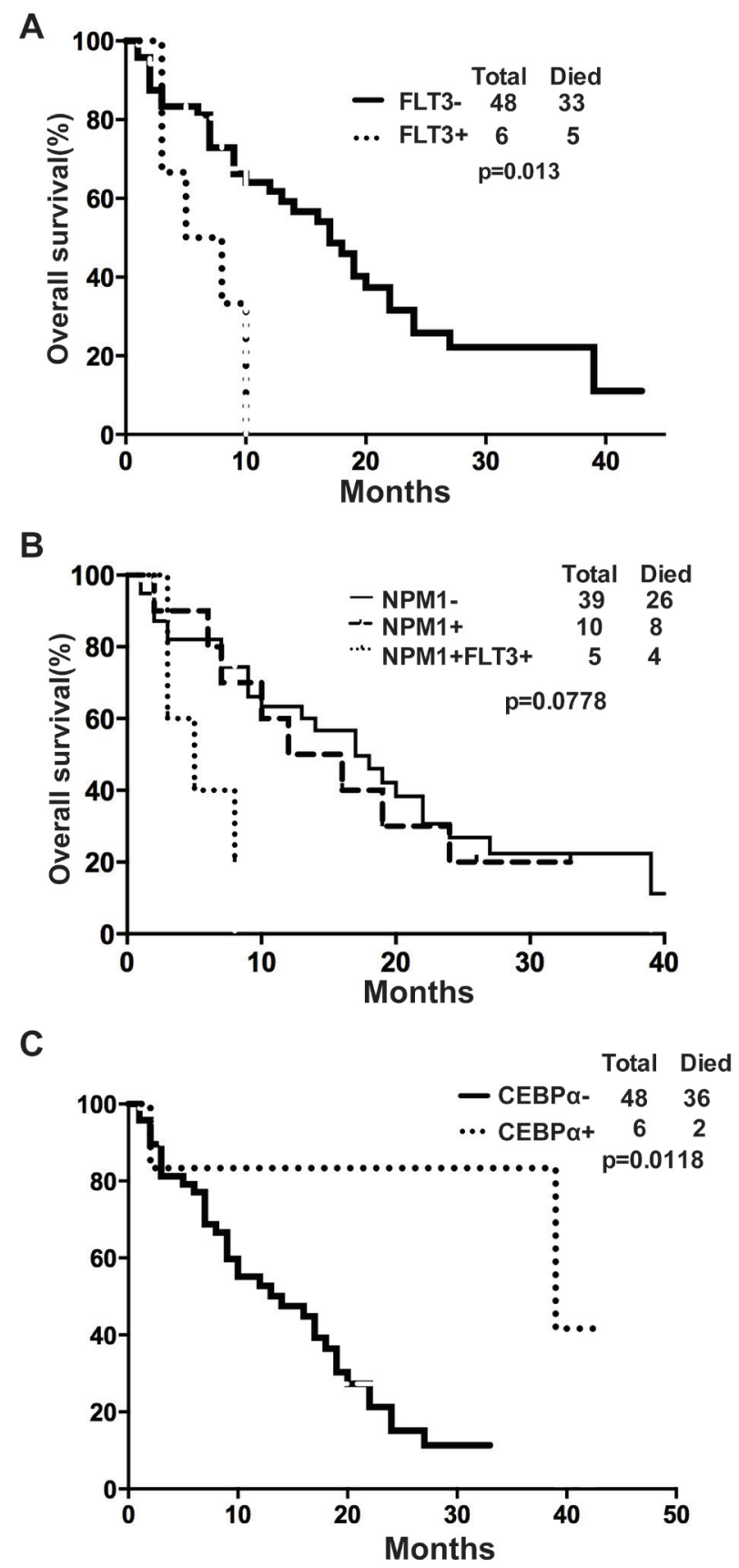

Figure 4: Gene mutation affected the overall survival of elderly patients with AML. (A) OS difference in patients with or without FLT3-ITD mutation; (B) OS difference in patients with or without NPM1 mutations; (C) OS difference in patients with or without $C E B P \alpha$ mutations. of treatment, 4 patients (4.4\%) with ECOG 3 died of severe infection, cardiac dysfunction or intracranial hemorrhage. Of the 70 responding patients, 16 remain CR during follow-up, 51 relapsed in remission (19 relapsed due to discontinued further chemotherapy), 3 died of consolidation chemotherapy.

\section{DISCUSSION}

This phase II study represents, to the best of our knowledge, the first reported prospective trial investigating the use of decitabine in combination with G-CSF, lowdose aclarubicin and cytarabine as the first-line therapy for elderly patients with AML. It was carried out to evaluate the efficacy of D-CAG combination therapy and assess the adverse events in those elderly patients with AML.

Several rationales guide us to design the $\mathrm{D}-\mathrm{CAG}$ regimen to treat elderly AML patient. DNA methylation was dose dependent with a plateau and correlated with response to decitabine at low $\left(5-20 \mathrm{mg} / \mathrm{m}^{2} / \mathrm{d}\right)$ but not high doses [19]. DNMT1 depletion by decitabine is S-phase dependent, and is more extensive in actively cycling cells [20]. G-CSF priming induced G0/G1 phase leukemia cells into $\mathrm{S}$ phase and caused leukemia cells response to decitabine. In addition, the combination of decitabine and cytarabine showed an additive or synergistic effect on cell death in human leukemia cell lines in vitro[7]. Those previous studies suggest that D-CAG regimen may achieve better outcomes in elderly AML patients. Our study showed that decitabine in combination with CAG was well tolerated and effective with CR of $77.7 \%$ in elderly patients with previously untreated AML. Our study also revealed a CR of $76.3 \%$ and median survival of 10 months, while only 2 patients $(4.76 \%)$ died within 8 weeks in 42 patients $\geq 70$ years of age. The patients aged $\geq 70$ years benefit more from decitabine in combination with low-dose CAG in comparison with patients from our previous study. With CAG treatment, the ORR and CR were $72.0 \%$ and $58.0 \%$, respectively [14]. The median OS was 14 months. In comparison, with D-CAG treatment, ORR and CR were $82.4 \%$ and $64.7 \%$, respectively, after 1 cycle of therapy. The ORR in patients aged $<70$ years was $83.0 \%$ and $81.6 \%$ in patients aged $\geq 70$ years. There was a significantly longer median OS in patients with response (16 months). Compared to cytarabine-based intensive chemotherapy, our D-CAG-based intensive chemotherapy also showed a higher CR and a longer median survival. A recent study of the cytarabine-based intensive chemotherapy on 446 patients $\geq 70$ years of age with AML obtained a CR of $45 \%$, and a median survival of 4.6 months in all patients, 13.8 months in CR patients, and 8 -weeks mortality was $36 \%$ [3].

Our study also showed that CR might be an important index to predict the survival probability of elderly patients with AML. In this phase II trial, the survival probability of patients with CR was significantly 
higher than that of patients without response to D-CAG treatment. These results were comparable to other studies, suggesting that $\mathrm{CR}$ might be required for prolonged survival [21].

An interesting finding from this study was that the CR rate in patients with poor karyotype was similar to that in other patients. Consistent with results from an earlier study, there was a clear benefit for patients with both CR and CCyR after induction of chemotherapy [22,23]. Similarly, another study showed that 19/61 (31.2\%) MDS patients with clonal chromosomal abnormalities achieved major cytogenetic responses after a median of $>2$ cycles (3 cycles) of treatment with low-dose decitabine and had a prolonged OS. Those studies suggested that decitabine induction might be important for patients with poor karyotype. We also found that our patients with "highrisk" chromosomal abnormalities, such as chromosome 7 abnormalities and complex abnormalities, tend to have a longer OS (8.5 months) than that previously reported $[14,24]$. Decitabine may inhibit those chromosomal abnormalities induced DNA hypermethylation and inactivated genes and cause the longer OS of AML patients.

The prognostic impact of NPM1,CEBP $\alpha$ and FLT3-ITD mutations, was first established by cytogenentic analysis in AML patients who were $<60$ years of age [30]. Similarly, the relative favorable effect of NPM1 mutation and $C E B P \alpha$ mutation and the unfavorable effect of FLT3-ITD mutation were also manifested in elderly AML patients [25-27]. However, there has not been any favorable effect in elderly patients with the NPM1 mutation, in whom the 2-year OS rate was $19 \%$ in a combined SWOG/MRC data analysis [28]. Our study showed that the relative favorable OS was achieved in patients with $C E B P \alpha$ mutations, while the outcome in patients with FLT3-ITD was significantly poorer. Interesting, NPM1 mutation itself did not lead to a better survival. These results should be explained with caution, as the patient's sample pool in each group was relative small. Therefore, the role of NPM1 mutation or other gene mutations, such as IDH1, IDH2 and TET2 et.al, in the response of elderly AML patients to D-CAG needs further in-depth investigation.

Our results also suggested that clinical benefit from decitabine in combination with low-dose CAG treatment might be linked to the ability to suppress the abnormal clone. However, we found that decitabine alone or in combination with other agents failed to eradicate the abnormal clone. In our study, 11 out of 18 patients with CCyR had a cytogenetic relapse (6 BM relapse and 1 extramedullary relapse). These results were consistent with earlier findings, which suggested that the initial cytogenetic clone can relapse upon D-CAG treatment and D-CAG regimen may not eradicate the abnormal clone $[29,30]$.

In conclusion, decitabine in combination with low- dose CAG treatment appeared to be a feasible, safe and effective for elderly patients with AML. Early results of this prospective trial demonstrated the effectiveness of decitabine-CAG combination and, thus far, limited treatment-related adverse effects in elderly patients. Additional follow-up and more robust phase 2 studies are needed to assess the efficacy and safety of D-CAG-based chemotherapy in elderly patients with AML.

\section{MATERIALS AND METHODS}

\section{Study population}

For this multi-center, phase II study, we recruited elderly patients with AML from 11 medical centers in China from October 2010 through March 2013. This study was registered at www.chictr.org as ChiCTRONC-11001700. Patients aged $\geq 60$ years with newly diagnosed de novo or secondary AML according to the International Working Group (IWG) criteria [31] who refused or were not candidates for intensive chemotherapy were eligible. All patients had an Eastern Cooperative Oncology Group (ECOG) performance status (PS) of 0-3 with the creatinine level and total bilirubin of $\leq 2 \mathrm{mg} / \mathrm{dL}$. Exclusion criteria included acute promyelocytic leukemia, another malignancy without remission. Patients must not have previous chemotherapy (other than hydroxyurea) for any myeloid disorder. Comorbidities were assessed using hematopoietic cell transplantation comorbidity index (HCT-CI)[32]. This study was performed in accordance with the Declaration of Helsinki and all patients provided written informed consent. All study procedures and informed consent forms were approved by Institutional Review Board.

\section{Study design}

All patients were treated with decitabine of $15 \mathrm{mg} /$ $\mathrm{m}^{2}$ intravenously over $4 \mathrm{~h}$ for 5 consecutive days (day 1-5) and G-CSF of $300 \mu \mathrm{g} /$ day (day 0-9) for priming combined with cytarabine of $10 \mathrm{mg} / \mathrm{m}^{2} \mathrm{q} 12 \mathrm{~h}$ for 7 days (day 3-9), aclarubicin of $10 \mathrm{mg} /$ day for 4 days (day 3-6) (D-CAG). The G-CSF priming was discontinued if white blood count (WBC) was $>20 \times 10^{9} / \mathrm{L}$. Hydroxyurea was permitted as rescue medication to control $\mathrm{WBC}$ to $<5.0 \times 10^{9} / \mathrm{L}$ and but was discontinued at least $24 \mathrm{~h}$ before decitabine treatment.

Up to two cycles of induction therapy were allowed if response was not achieved. Patients who achieved CR accepted the next cycle treatment for recovery of hematopoiesis and resolution of all toxicities. Patients who did not achieve CR or partial remission (PR) after the second cycle of induction therapy were offered alternative therapies. Post-remission therapy consisted of 4-6 cycles at the discretion of attending physician, including alternate 
D-CAG and conventional chemotherapy [cytarabine (100 $\mathrm{mg} / \mathrm{m}^{2}$ for 7 days) in combination with homoharringtonine ( $2 \mathrm{mg} / \mathrm{m}^{2} /$ day for 7 days) or an anthracyclin agent, such as daunorubicin (30 mg/m² for 3 days)]. In patients aged $\geq 70$ years and/ or with $E C O G \geq 2$, or with hypoplasia/ cytopenia, doses were reduced to $70 \%$ of scheduled dose levels in subsequent cycles. Treatment was continued until relapse or progressive disease, death, or unacceptable toxicity occurred, or patients/physicians requested the discontinuity. All patients received antimicrobials, supportive care, and transfusions of blood products according to the institutional guidelines.

Treatment responses were defined according to the modified 2003 IWG criteria [31]. Morphologic CR included normalization of bone marrow blasts $(\leq 5 \%$ blasts) and peripheral blood counts (absolute neutrophil count $\geq 1.0 \times 10^{9} / \mathrm{L}$ and platelet $\left.>100 \times 10^{9} / \mathrm{L}\right)$. PR was defined as morphologic CR and $5-15 \%$ blasts with a decrease of at least $50 \%$ of total bone marrow blasts. Time to hematopoietic recovery was measured from the last day of chemotherapy to the time when the neutrophil count was $>0.5 \times 10^{9} / \mathrm{L}$ and platelet count was more than $20 \times 10^{9} / \mathrm{L}$. All other patients were considered as nonresponders.

Conventional cytogenetic evaluation was also performed after induction therapy. The overall survival (OS) was measured from the time at beginning of the study to death (any cause). Disease-free survival (DFS) was calculated from the date of remission to an event, including resistance, PR, relapse, or death. Early induction mortality within 4 weeks was calculated.

Toxicities were assessed according to Common Terminology Criteria For Adverse Events (CTCAE) version 3.0. Safety was assessed using adverse events, physical examinations, vital signs, and central laboratory assessments.

\section{Cytogenetic and mutation analysis}

Bone marrow (BM) cells were harvested directly or after 1-3 days of unstimulated culture, as described previously. Metaphase cells were banded via an improved heat treatment and R-banding method. Genomic DNA was isolated from BM specimens. Mutation analysis of three relevant molecular marker genes (NPM1, $C E B P \alpha$ and FLT3-ITD) was carried out as described previously[15]. The mutation was determined by collection of the mutated polymerase chain reaction fragment followed by sequencing. The primers used to detect the gene mutation are listed. NPM1 mutation forward primer: TTAACTCTCTGGTGGTAGAATGAA, NPM1 mutation reverse primer: CAAGACTATTTGCCATTCCTAAC; FLT3-ITD forward primer: GCAATTTAGGTATGAAAGCCAGC, FLT3-ITD reverse primer: CTTTCAGCATTTTGACGGCAACC; $C E B P \alpha$ mutation forward primer:
TCGGCCGACTTCTACGAG, $C E B P \alpha$ mutation reverse primer: GCTTGGCTTCATCCTCCTC; $C E B P \alpha$ mutation forward primer: GAGGAGGATGAAGCCAAGC, $C E B P \alpha$ mutation reverse primer: GTTGCCCATGGCCTTGAC.

\section{Statistical analysis}

Survival curves were plotted by the Kaplan-Meier method and compared by using the log-rank (MantekCox) test stratified by baseline age, cytogenetic risk, and response after treatment. In order to analyze the related impact of each variant on survival, hazard ratios (HRs) and $95 \%$ confidence interval (CI) were calculated by using a Cox proportional hazards model stratified by gender, disease, age, cytogenetic risk, WBC at diagnosis, BM blasts, ECOG PS and HCT-CI, respectively. Differences in subgroups by different covariates were evaluated by using the chi-square test for nominal values. A $p$ value $<0.05$ was considered significant.

\section{ACKNOWLEDGEMENTS}

We appreciate all patients and investigators from the participating 11 institutions.

\section{Disclosure of potential conflicts of interest}

The authors declared that no conflict interests.

\section{Author contribution}

SQ and JL designed the study, searched the published work, analyzed and interpreted data, and wrote the manuscript. YC, YZ, MH, JX, LP, LD, RZ, SZ, HZ, HL, PL, HQ, HW, JZ, YX, YL, KY, LP, JW, JD, JG, SZ, JS enrolled patients, and provided of study material and interpreted data. All authors reviewed the report and approved the final version.

\section{Grant support}

This study was supported by the National Natural Science Foundation of the People's Republic of China (No. 81070437, 81270614, 81200362, 81070456, 81270652), National Public Health Grand Research Foundation (No.201202017), The project was funded by Priority Academic Program Development of Jiangsu Higher Education Institute (No. JX10231801) and Jiangsu Province Health Agency (K201107). The project was also funded by Jiangsu TePin Professor Program, Department of Education of Jiangsu Province and Jiangsu TePin Medical Expert Program, Health and Family Planning Commission of Jiangsu Province. 


\section{REFERENCES}

1. Estey EH. Older adults: should the paradigm shift from standard therapy? Best Pract Res Clin Haematol. 2008;21(1):61-66.

2. Juliusson G, Antunovic P, Derolf A, Lehmann S, Mollgard L, Stockelberg D, Tidefelt U, Wahlin A, Höglund M. Age and acute myeloid leukemia: real world data on decision to treat and outcomes from the Swedish Acute Leukemia Registry. Blood. 2009;113(18):4179-4187.

3. Estey E. Acute myeloid leukemia and myelodysplastic syndromes in older patients. J Clin Oncol. 2007;25(14):1908-1915.

4. Lubbert M, Ruter BH, Claus R, Schmoor C, Schmid M, Germing U, Kuendgen A, Rethwisch V, Ganser A, Platzbecker U, Galm O, Brugger W, Heil G, Hackanson B, Deschler B, Döhner K, et al. A multicenter phase II trial of decitabine as first-line treatment for older patients with acute myeloid leukemia judged unfit for induction chemotherapy. Haematologica. 2012;97(3):393-401.

5. Kantarjian HM, Thomas XG, Dmoszynska A, Wierzbowska A, Mazur G, Mayer J, Gau JP, Chou WC, Buckstein R, Cermak J, Kuo CY, Oriol A, Ravandi F, Faderl S, Delaunay J, Lysák D, et al. Multicenter, randomized, openlabel, phase III trial of decitabine versus patient choice, with physician advice, of either supportive care or lowdose cytarabine for the treatment of older patients with newly diagnosed acute myeloid leukemia. J Clin Oncol. 2012;30(21):2670-2677.

6. Quintas-Cardama A, Ravandi F, Liu-Dumlao T, Brandt M, Faderl S, Pierce S, Borthakur G, Garcia-Manero G, Cortes J, Kantarjian H. Epigenetic therapy is associated with similar survival compared with intensive chemotherapy in older patients with newly diagnosed acute myeloid leukemia. Blood. 2012;120(24):4840-4845.

7. Qin T, Youssef EM, Jelinek J, Chen R, Yang AS, GarciaManero G, Issa JP. Effect of cytarabine and decitabine in combination in human leukemic cell lines. Clin Cancer Res. 2007;13(14):4225-4232.

8. Pinto A, Attadia V, Fusco A, Ferrara F, Spada OA, Di Fiore PP. 5-Aza-2'-deoxycytidine induces terminal differentiation of leukemic blasts from patients with acute myeloid leukemias. Blood. 1984;64(4):922-929.

9. Shen L, Kantarjian H, Guo Y, Lin E, Shan J, Huang X, Berry D, Ahmed S, Zhu W, Pierce S, Kondo Y, Oki Y, Jelinek J, Saba H, Estey E, Issa JP. DNA methylation predicts survival and response to therapy in patients with myelodysplastic syndromes. J Clin Oncol. 2010;28(4):605613.

10. Kurimoto M, Matsuoka H, Hanaoka N, Uneda S, Murayama T, Sonoki T, Nakakuma H. Pretreatment of leukemic cells with low-dose decitabine markedly enhances the cytotoxicity of gemtuzumab ozogamicin. Leukemia. $2013 ; 27(1): 233-235$.
11. Mayer J, Arthur C, Delaunay J, Mazur G, Thomas XG, Wierzbowska A, Ravandi F, Berrak E, Jones M, Li Y, Kantarjian HM. Multivariate and subgroup analyses of a randomized, multinational, phase 3 trial of decitabine vs treatment choice of supportive care or cytarabine in older patients with newly diagnosed acute myeloid leukemia and poor- or intermediate-risk cytogenetics. BMC Cancer. 2014;14:69.

12. Scandura JM, Roboz GJ, Moh M, Morawa E, Brenet F, Bose JR, Villegas L, Gergis US, Mayer SA, Ippoliti CM, Curcio TJ, Ritchie EK, Feldman EJ. Phase 1 study of epigenetic priming with decitabine prior to standard induction chemotherapy for patients with AML. Blood. 2011;118(6):1472-1480.

13. Klco JM, Spencer DH, Lamprecht TL, Sarkaria SM, Wylie T, Magrini V, Hundal J, Walker J, Varghese N, ErdmannGilmore P, Lichti CF, Meyer MR, Townsend RR, Wilson RK, Mardis ER, Ley TJ. Genomic impact of transient lowdose decitabine treatment on primary AML cells. Blood. 2013;121(9):1633-1643.

14. Qian SX, Li JY, Tian T, Shen YF, Jiang YQ, Lu H, Wu $\mathrm{HX}$, Zhang SJ, Xu W. Effect of low-dose cytarabine and aclarubicin in combination with granulocyte colonystimulating factor priming (CAG regimen) on the outcome of elderly patients with acute myeloid leukemia. Leuk Res. 2007;31(10):1383-1388.

15. Schwartsmann G, Fernandes MS, Schaan MD, Moschen M, Gerhardt LM, Di Leone L, Loitzembauer B, Kalakun L. Decitabine (5-Aza-2'-deoxycytidine; DAC) plus daunorubicin as a first line treatment in patients with acute myeloid leukemia: preliminary observations. Leukemia. 1997;11 Suppl 1:S28-31.

16. Blum W, Schwind S, Tarighat SS, Geyer S, Eisfeld AK, Whitman S, Walker A, Klisovic R, Byrd JC, Santhanam R, Wang H, Curfman JP, Devine SM, Jacob S, Garr C, Kefauver C, et al. Clinical and pharmacodynamic activity of bortezomib and decitabine in acute myeloid leukemia. Blood. 2012;119(25):6025-6031.

17. Qiao C, Zhang R, Hong M, Wang L, Zhang JF, Wu YJ, Qiu HR, Qiu HX, Qian SX, Lu H, Zhang SJ, Li JY. Heterogeneous leukemic clones identified by NPM1 mutation analysis in patient with acute monocytic leukemia. Leuk Lymphoma. 2012;53(5):886-890.

18. Frohling S, Schlenk RF, Breitruck J, Benner A, Kreitmeier S, Tobis K, Döhner H, Döhner K; AML Study Group Ulm. Acute myeloid leukemia. Prognostic significance of activating FLT3 mutations in younger adults (16 to 60 years) with acute myeloid leukemia and normal cytogenetics: a study of the AML Study Group Ulm. Blood. 2002;100(13):4372-4380.

19. Falini B, Mecucci C, Tiacci E, Alcalay M, Rosati R, Pasqualucci L, La Starza R, Diverio D, Colombo E, Santucci A, Bigerna B, Pacini R, Pucciarini A, Liso A, Vignetti M, Fazi P, et al. Cytoplasmic nucleophosmin in acute myelogenous leukemia with a normal karyotype. $\mathrm{N}$ 
Engl J Med. 2005;352(3):254-266.

20. Wen XM, Lin J, Yang J, Yao DM, Deng ZQ, Tang CY, Xiao GF, Yang L, Ma JC, Hu JB, Qian W, Qian J. Double CEBPA mutations are prognostically favorable in non-M3 acute myeloid leukemia patients with wild-type NPM1 and FLT3-ITD. Int J Clin Exp Pathol. 2014;7(10):6832-6840.

21. Yang AS, Doshi KD, Choi SW, Mason JB, Mannari RK, Gharybian V, Luna R, Rashid A, Shen L, Estecio MR, Kantarjian HM, Garcia-Manero G, Issa JP. DNA methylation changes after 5-aza-2-deoxycytidine therapy in patients with leukemia. Cancer Res. 2006;66(10):5495-503.

22. Hu Z, Negrotto S, Gu X, Mahfouz R, Ng KP, Ebrahem Q, Copelan E, Singh H, Maciejewski JP, Saunthararajah Y. Decitabine maintains hematopoietic precursor selfrenewal by preventing repression of stem cell genes by a differentiation-inducing stimulus. Mol Cancer Ther. 2010;9(6):1536-1543.

23. Lee JH, Jang JH, Park J, Park S, Joo YD, Kim YK, Kim HG, Choi CW, Kim SH, Park SK, Park E, Min YH. A prospective multicenter observational study of decitabine treatment in Korean patients with myelodysplastic syndrome. Haematologica. 2011;96(10):1441-1447.

24. Lübbert M, Wijermans P, Kunzmann R, Verhoef G, Bosly A, Ravoet C, Andre M, Ferrant A. Cytogenetic responses in high-risk myelodysplastic syndrome following low-dose treatment with the DNA methylation inhibitor 5-aza-2'deoxycytidine. Br J Haematol. 2001;114(2):349-357.

25. Kuendgen A, Bug G, Ottmann OG, Haase D, Schanz J, Hildebrandt B, Nachtkamp K, Neukirchen J, Dienst A, Haas R, Germing U, Gattermann N. Treatment of poor-risk myelodysplastic syndromes and acute myeloid leukemia with a combination of 5-azacytidine and valproic acid. Clin Epigenetics. 2011;2(2):389-399.

26. Perrot A, Luquet I, Pigneux A, Mugneret F, Delaunay J, Harousseau JL, Barin C, Cahn JY, Guardiola P, Himberlin C, Recher C, Vey N, Lioure B, Ojeda-Uribe M, Fegueux $\mathrm{N}$, Berthou C,et al. Dismal prognostic value of monosomal karyotype in elderly patients with acute myeloid leukemia: a GOELAMS study of 186 patients with unfavorable cytogenetic abnormalities. Blood. 2011;118(3):679-685.

27. Becker H, Marcucci G, Maharry K, Radmacher MD, Mrózek K, Margeson D, Whitman SP, Wu YZ, Schwind S, Paschka P, Powell BL, Carter TH, Kolitz JE, Wetzler M, Carroll AJ, Baer MR, et al. Favorable prognostic impact of NPM1 mutations in older patients with cytogenetically normal de novo acute myeloid leukemia and associated gene- and microRNA-expression signatures: a Cancer and Leukemia Group B study. J Clin Oncol. 2010;28(4):596604.

28. Whitman SP, Maharry K, Radmacher MD, Becker H, Mrózek K, Margeson D, Holland KB, Wu YZ, Schwind $\mathrm{S}$, Metzeler KH, Wen J, Baer MR, Powell BL, Carter TH, Kolitz JE, Wetzler M, et al. FLT3 internal tandem duplication associates with adverse outcome and gene- and microRNA-expression signatures in patients 60 years of age or older with primary cytogenetically normal acute myeloid leukemia: a Cancer and Leukemia Group B study. Blood. 2010;116(18):3622-3626.

29. Schlenk RF, Taskesen E, van Norden Y, Krauter J, Ganser A, Bullinger L, Gaidzik VI, Paschka P, Corbacioglu A, Göhring G, Kündgen A, Held G, Götze K,Vellenga E, Kuball J, Schanz U, et al. The value of allogeneic and autologous hematopoietic stem cell transplantation in prognostically favorable acute myeloid leukemia with double mutant CEBPA. Blood. 2013;122(9):1576-1582.

30. Sorror ML, Estey E. Allogeneic hematopoietic cell transplantation for acute myeloid leukemia in older adults. Hematology/the Education Program of the American Society of Hematology.2014;21-33.

31. Cheson BD, Bennett JM, Kopecky KJ, Buchner T, Willman CL, Estey EH, Schiffer CA, Doehner H, Tallman MS, Lister TA, Lo-Coco F, Willemze R, Biondi A, Hiddemann W, Larson RA, Löwenberg B, et al. Revised recommendations of the International Working Group for Diagnosis, Standardization of Response Criteria, Treatment Outcomes, and Reporting Standards for Therapeutic Trials in Acute Myeloid Leukemia. J Clin Oncol. 2003;21(24):4642-4649.

32. Sorror ML, Giralt S, Sandmaier BM, De Lima M, Shahjahan M, Maloney DG, Deeg HJ, Appelbaum FR, Storer B, Storb R. Hematopoietic cell transplantation specific comorbidity index as an outcome predictor for patients with acute myeloid leukemia in first remission: combined FHCRC and MDACC experiences. Blood. 2007;110(13):4606-4613. 